International Journal of Wireless \& Mobile Networks (IJWMN) Vol. 3, No. 5, October 2011

\title{
A NOVEL MULTIBAND KOCH LOOP ANTENNA USING FRACTAL GEOMETRY FOR WIRELESS COMMUNICATION SYSTEM
}

\author{
Rajeev Mathur ${ }^{1}$, Sunil Joshi ${ }^{2}$, Krishna C Roy ${ }^{3}$ \\ ${ }^{1}$ Department of ECE, Suresh Gyan Vihar University, Jaipur, Rajasthan, India \\ Rmathur_2000@yahoo.com \\ ${ }^{2}$ College of Engineering \& Technology, MPUAT, Udaipur, India \\ suniljoshi7erediffmail.com \\ ${ }^{3}$ Pecific Institute of Technology, Udaipur, India \\ roy.krishnaerediffmail.om
}

\begin{abstract}
The paper present a novel multi-band compact antenna designed on the theory of fractal geometry. The antenna is fabricated on a FR4 substrate. The performance of the proposed antenna design is analyzed and the results are compared with the simulations using IE-3D tool. The relevant antenna performance parameters of the proposed design viz. resonant bands, return loss, bandwidth and gain are reported and discussed. The VSWR of the antenna is less than 2 for six resonant bands in the vicinity of $1.15 \mathrm{GHz}, 2.0$ $\mathrm{GHz}, 3.17 \mathrm{GHz}, 3.6 \mathrm{GHz}, 4.17 \mathrm{GHz}$ and $5.91 \mathrm{GHz}$. The performance results exhibited by the proposed antenna makes it extremely useful for the future generation of wireless broadband communication systems.
\end{abstract}

\section{KEYWORDS}

Fractal Antenna, Multiband, Return Loss, Koch Dipole, Loop Antenna.

\section{INTRODUCTION}

'Fractal' term was first coined by Benoit Mandelbrot in 1983 to classify the structure whose dimensions were not whole numbers. A mathematical description of dimension is based on how the "size" of an object behaves as the linear dimension increases. In one dimension consider a line segment, if the linear dimension of this line segment is doubled then obviously the length (characteristic size) of the line has doubled. In two dimensions, if the linear dimensions of a rectangle is doubled then the characteristic size, the area, increases by a factor of 4 . In three dimensions, if the linear dimension of a box are doubled then its volume increases by a factor of 8 . This relationship between dimension $\mathrm{D}$, linear scaling $\mathrm{L}$ and the resulting increase in size $\mathrm{S}$ can be generalised and represented mathematically as [1]

$$
\mathrm{S}=\mathrm{L}^{\mathrm{D}} \quad \ldots 1
$$

This is just telling us mathematically what we know from everyday experience. If we scale a two dimensional object for example then the area increases by the square of the scaling. If we scale a three dimensional object the volume increases by the cube of the scale factor. Rearranging the above expression in terms of logarithmic expression as below

DOI : 10.5121/ijwmn.2011.3513 


$$
\mathrm{D}=\log (\mathrm{S}) / \log (\mathrm{L}) \quad \ldots .2
$$

This relationship holds for all Euclidean shapes. But in natural world there are many shapes which do not conform to the integer based description of dimensions. There are objects which appear to be curves which cannot be described with integer number. There are shapes that lie in a plane i.e. two dimensional $(\mathrm{D}=2$ in the expression), but if they are linearly scaled by a factor $\mathrm{L}$, the area does not increase by L squared but by some non integer amount. These geometries are called fractals! [1]

Fractals are used to describe the branching of tree leaves and plants, the sparse filling of water vapour that forms clouds, the random erosion that carves mountain faces, that jaggedness of coastlines and bark, and many more examples in nature[1]. One of the properties of fractals geometry is that it can have an infinite length while fitting in a finite volume. The radiation characteristic of any electromagnetic radiator depends on electrical length of the structure [2]. Using the property of fractal geometry, we may increase the electrical length of an antenna, keeping the volume of antenna same. Thus a new configurations for radiators and reflectors may be developed to give better performance in terms of gain, bandwidth etc. There are an infinite number of possible geometries that are available to try as a design of fractal antenna. One of the important benefits of fractal antenna is that we get more than one resonant band.

The Simplest example of antenna using fractal geometry is given by the Von Koch, researcher. The method of creating this shape is to repeatedly replace each line segment with the following 4 line segments. The process starts with a single line segment and continues for ever. The first few iterations of this procedure are shown in Figure 1. First five iterations in the construction of the Koch curve are illustrated. Fractal dimension contains information about the self-similarity and the space-filling properties. The Fractal similarity Dimension (FD) is defined as [5]:

$$
\mathrm{FD}=\frac{\log (\mathrm{N})}{-\mathrm{Log}(1 / \varepsilon)}=\frac{\log (5)}{\log (3)}=1.46 \quad \ldots 3
$$

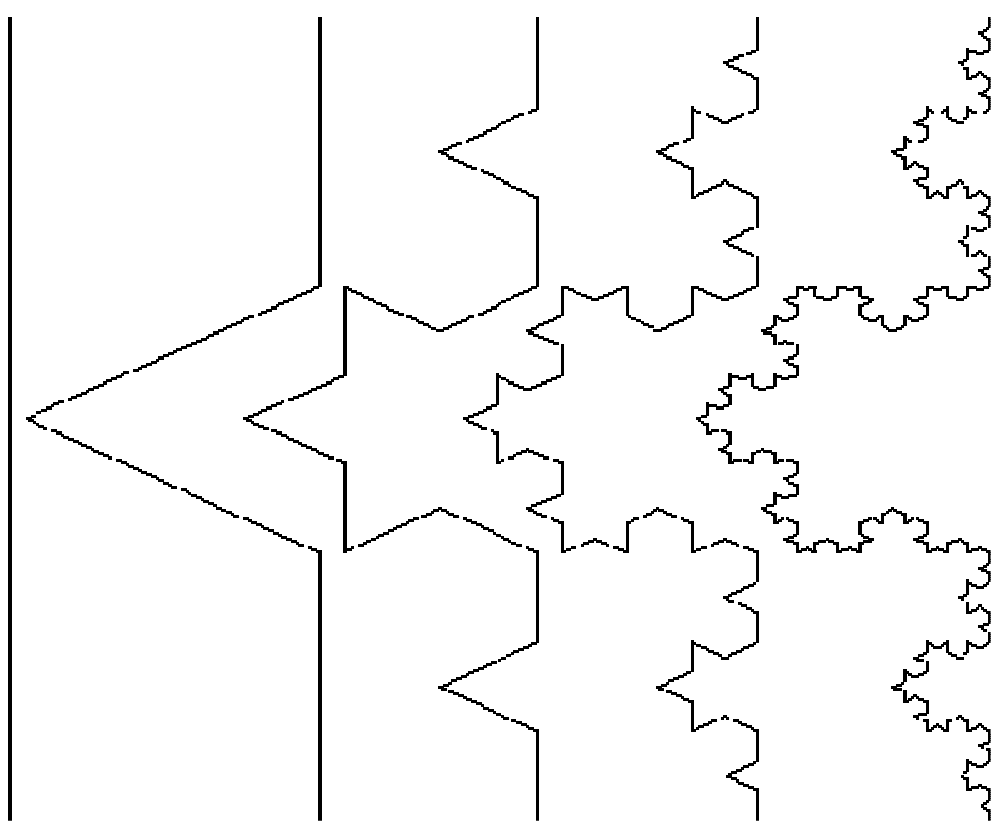

Figure 1. Koch fractal geometry.[5] 
Where $\mathrm{N}$ is the total number of distinct copies, and $(1 / \varepsilon)$ is the reduction factor value which means how will the length of the new side be, with respect to the original side length. Fractal shapes thus are defined as self similar shapes which are independent of size or scaling.[5]

\section{RELATED WORK}

Cohen N.L. have proposed a novel Koch monopole fractal antenna for the use in defence application. he concluded that the design space for the fractal antenna afford vast new opportunities in design and application, many realised and proven beyond theory [9]. Fractal antenna can obtain radiation pattern and input impedance similar to longer antenna, yet takes less area due to the many contour of shapes. Various fractal antenna design techniques is discussed by Nemanja POPRZEN \& Mico GACANOVIC. Koch Loop, Minkowski Loop, Siepinski Seive have been studies and two course of action have been concluded. Firstly, many more examples of fractals geometries could be applied to antenna and secondly, correlation could be drawn between fractal dimension and antenna performance. Figure 2, Figure 3, Figure 4 and Figure 5 below shows the various antennas so far studied [10].

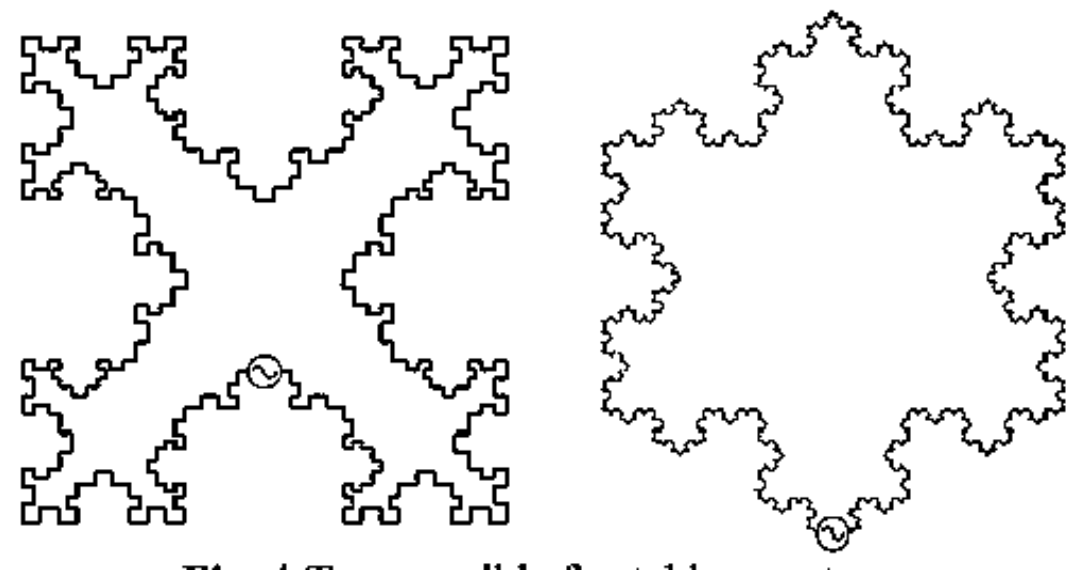

Figure 2. Fractal Loop Antennas [9].

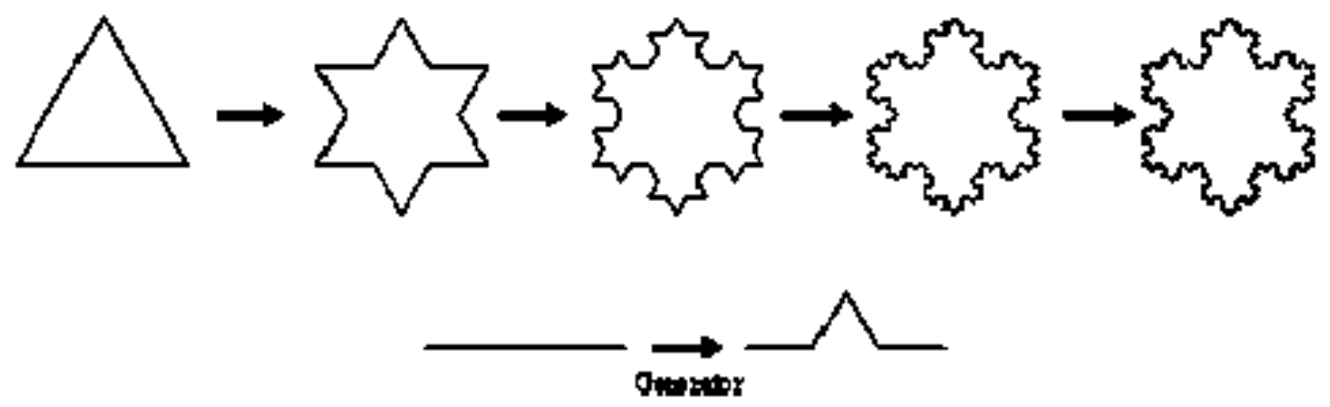

Figure 3. First Four Iteration of koch fractal antenna [10]. 
International Journal of Wireless \& Mobile Networks (IJWMN) Vol. 3, No. 5, October 2011
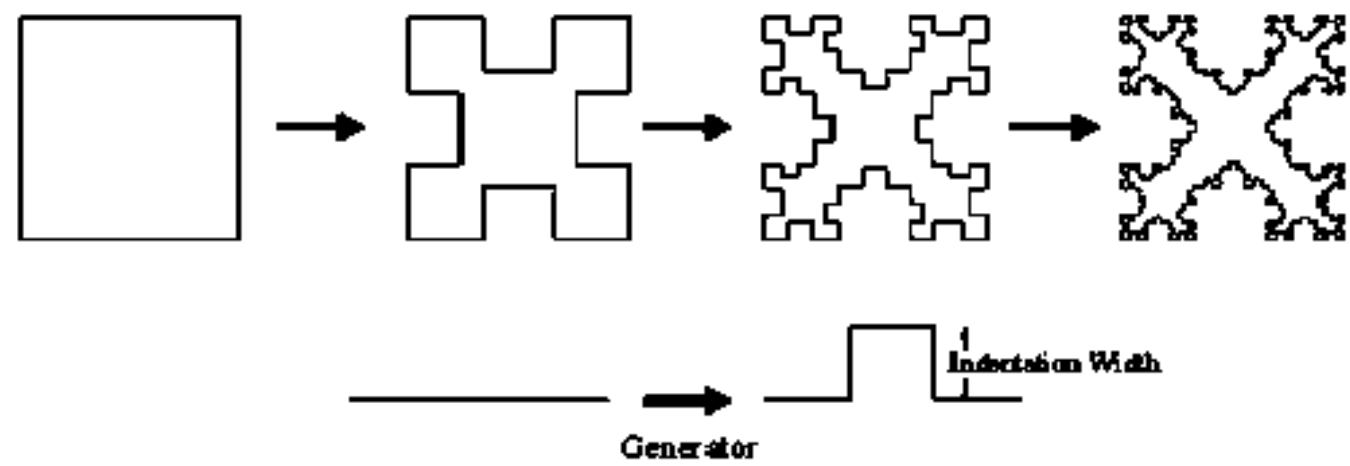

Figure 4. First four iteration of Minkowski Loop antenna [10].

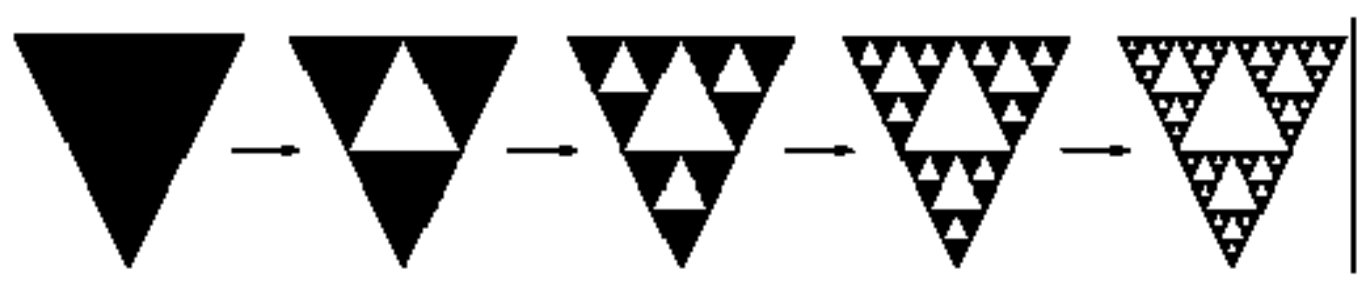

Figure 5. First four iteration of Siepinski Seive antenna [10].

Behavior of Koch monopole antenna has been analysed mathematically and experimentally by Carles Puente and Angel Cardama and it was observed that as the number of iteration in fractal antenna is increased, the $\mathrm{Q}$ of the antenna approaches the fundamental limits for small antenna. [11]. It has been also observed that in spite of small size fractal antenna prove to be good radiator. Ultimate application of this antenna is in mobile terminals where reduction of size is ultimate goal. It is possible to employ antenna that fits in small volume, but still have efficient performance. [11]

Many research groups are working on design of antenna based on fractal geometry which could prove to be an efficient radiator in wireless mobile communications applications.

\section{Proposed Antenna Design}

The width of the a microstrip patch antenna is calculted by [8]:

$$
W=\frac{1}{2 f_{r} \sqrt{\mu_{0} \epsilon_{0}}} \sqrt{\frac{2}{\epsilon_{r}+1}}=\frac{v_{0}}{2 f_{r}} \sqrt{\frac{2}{\epsilon_{r}+1}}
$$

The actual length and effective length of patch antenna is found as [8 ]

$$
\begin{aligned}
& L=\frac{1}{2 f_{r} \sqrt{\epsilon_{\text {reff }}} \sqrt{\mu_{0} \epsilon_{0}}}-2 \Delta L \\
& L_{\text {eff }}=L+2 \Delta L
\end{aligned}
$$

The dielectric constant, loss tangent and substrate height of designed antenna is choosen as 4.4, 0.025 and $1.588 \mathrm{~mm}$ respectively, for FR-4 substrate. The computed values of $\mathrm{W}$ and $\mathrm{L}_{\text {eff }}$ are 72.43 and $80.51 \mathrm{~mm}$ respectively.

The conventional dipole design technique is adopted to design the proposed Koch loop antenna. For a $2 \mathrm{GHz}$ frequency, wavelength is $150 \mathrm{~mm}$, a Dipole antenna length must be half of 
wavelength. The four dipoles are then arranged in the form of loop thereby increasing its physical length which comes out to $300 \mathrm{~mm}$. Resonant frequency now for loop will be $1 \mathrm{GHz}$.

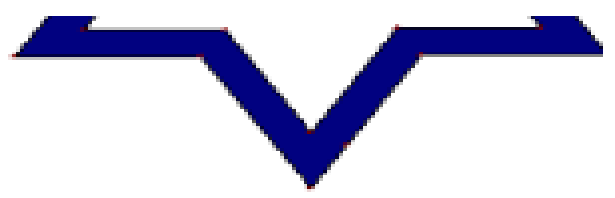

Figure 6. $2^{\text {nd }}$ iteration of koch dipole

$2^{\text {nd }}$ iteration of koch dipole is as shown in Figure 6. A final antenna is designed with the dimension further reduced to $1 / 3^{\text {rd }}$ of $2^{\text {nd }}$ iteration i.e. $25 \mathrm{~mm}$. The dipole width is choosen $2 \mathrm{~mm}$. This antenna is a simple planar structure with effective permittivity of substrate to be 4.4. Height of substrate is $1.588 \mathrm{~mm}$ with loss tangent of 0.025 . Ground Plane is considered to be infinite for simulation purpose; however, practically ground plane taken is $80 \mathrm{~mm} \mathrm{X} 80 \mathrm{~mm}$. CPW feed is chosen for this antenna. SMA connector of @50 ohms impedance is connected at feed port 1 and 2 as shown in Figure 7.

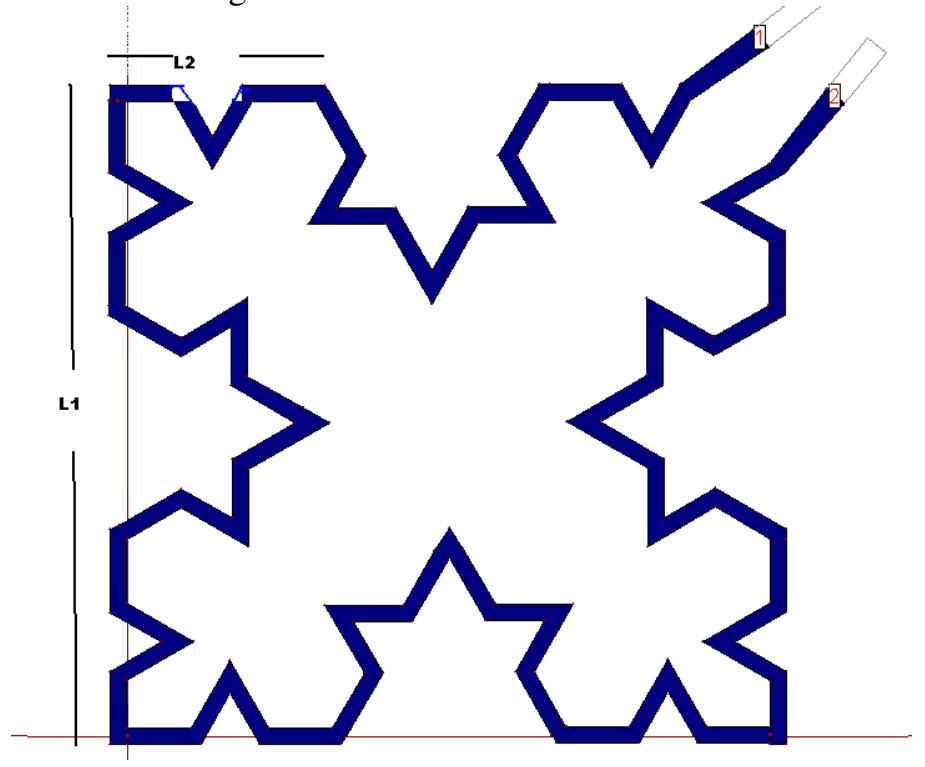

Figure 7. Koch Loop Antenna with Lengths L1 $=75 \mathrm{~mm}, \mathrm{~L} 2=25 \mathrm{~mm}$.

\section{Fabrication of Proposed antenna}

A Prototype structure of this antenna is fabricated in the lab using photolithography technique. Mask of the antenna is prepared and than complete structure was developed as shown in the Figure 8 . Commonly available substrate FR4 is used with copper cladding of $0.0004 \mathrm{~mm}$. The dimensions of the fabricated antenna are as given by Table 1 .

Table 1: Dimensions of Koch Loop Antenna

\begin{tabular}{|c|c|c|c|c|}
\hline Ltotal & Wtotal & $\begin{array}{c}\text { Width } \\
\text { of } \\
\text { Strip }\end{array}$ & L1 & L2 \\
\hline $80 \mathrm{~mm}$ & $80 \mathrm{~mm}$ & $2 \mathrm{~mm}$ & $75 \mathrm{~mm}$ & $25 \mathrm{~mm}$ \\
\hline
\end{tabular}


International Journal of Wireless \& Mobile Networks (IJWMN) Vol. 3, No. 5, October 2011

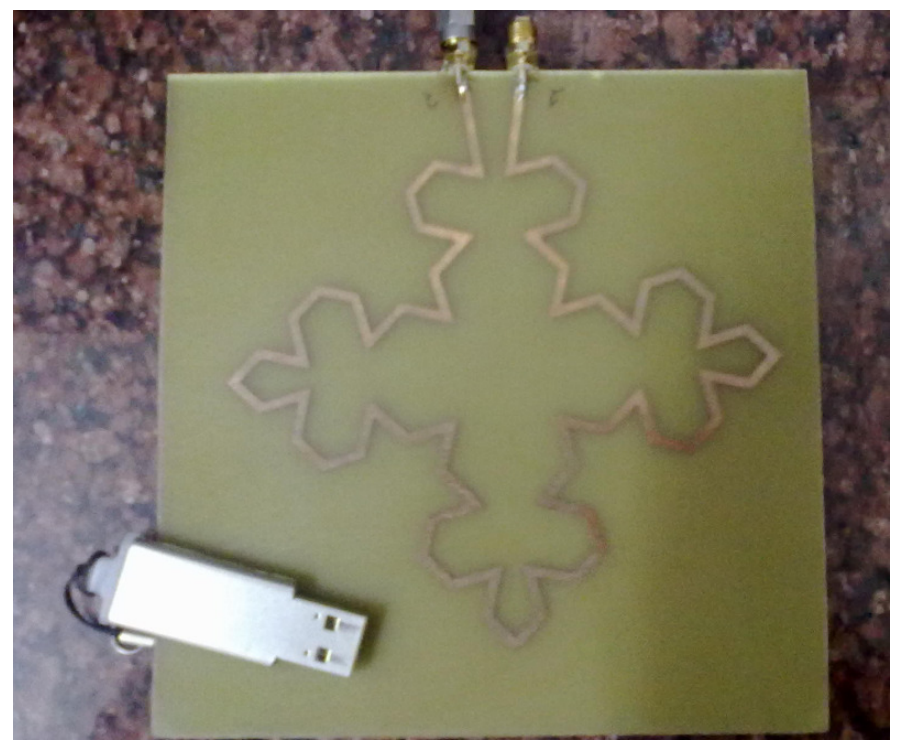

Figure 8. Fabricated Fractal Antenna

\section{RESUlt \& DiscusSion}

The resonant properties of proposed antenna have been obtained by designing the antenna structure using commercially available EM tool IE3D. The return loss profile is as shown in Figure 9, showing 7 bands with return loss well below $-10 \mathrm{~dB}$. The central frequencies of these bands are mentioned in the Table 2. Also, as shown in Figure 10, the VSWR obtained for these bands is found to be of the order of 2. It is observed that each small iterative element acts as a separate radiating dipole element leading to multiple resonant bands in addition to the fact that the entire loop acts as a radiating element. Besides, each small element contributes towards the increase in electrical length of antenna to increase radiating field $\mathrm{E}_{\theta}$. The axial ratio of the antenna is observed to be zero revealing it to be a linearly polarised antenna.

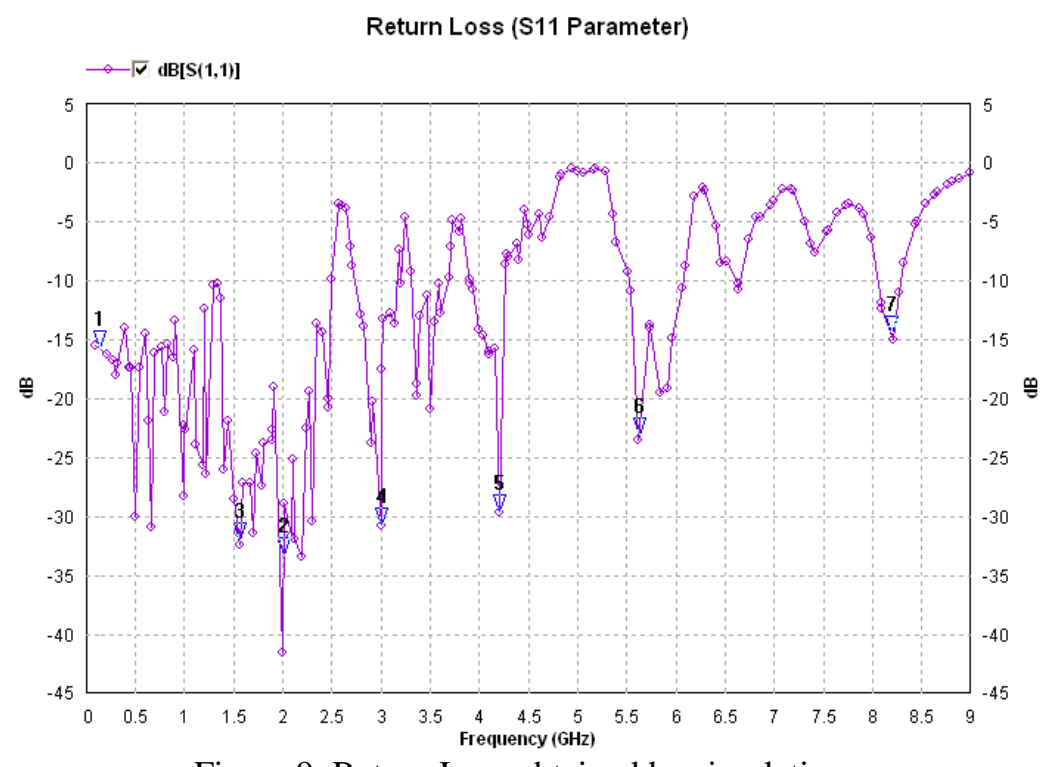

Figure 9. Return Loss obtained by simulation. 
International Journal of Wireless \& Mobile Networks (IJWMN) Vol. 3, No. 5, October 2011

Table 2: Resonant Frequencies of Koch Loop Antenna

\begin{tabular}{|l|l|l|}
\hline Points & Frequency & S11 in dB \\
\hline 1 & 0.50 & -30.76 \\
\hline 2 & 2.01 & -42.30 \\
\hline 3 & 1.56 & -32.04 \\
\hline 4 & 3.00 & -30.84 \\
\hline 5 & 4.2 & -29.70 \\
\hline 6 & 5.625 & -23.13 \\
\hline 7 & 8.19 & -14.55 \\
\hline
\end{tabular}

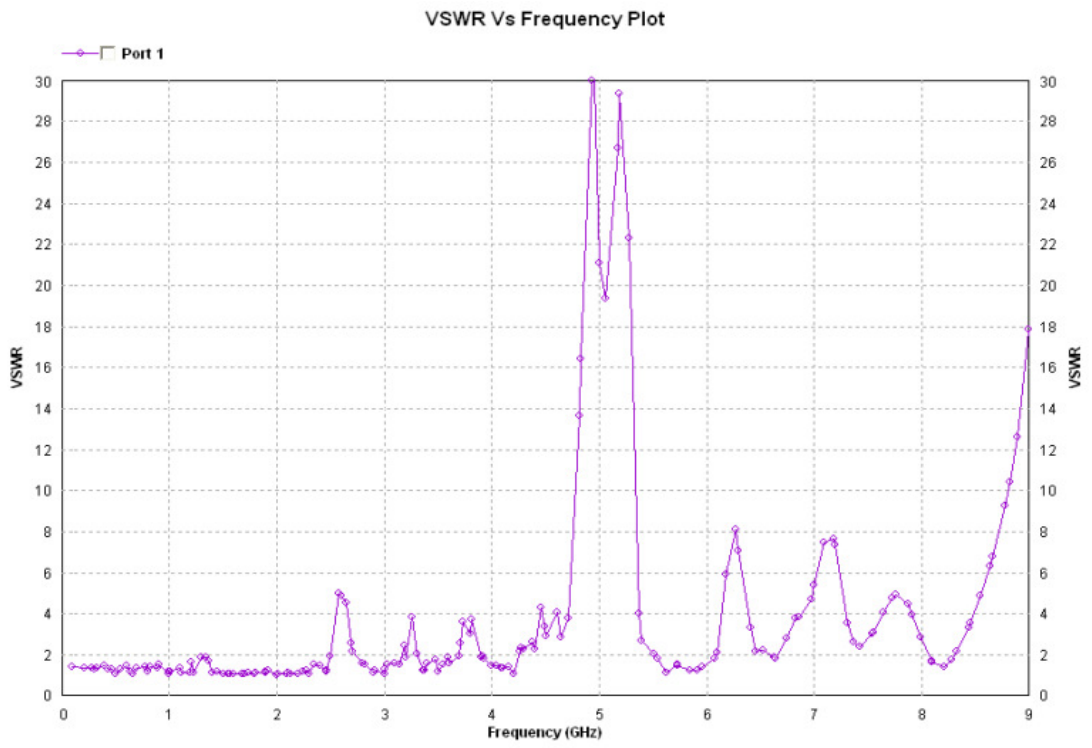

Figure 10. VSWR obtained by simulation

The measurement set up for testing the antenna performance is shown in Figure 11, which includes Vector Network Analyser (VNA) of Anritsu make, Signal Generator, Computer system and designed antenna. The VNA was first calibrated using calibration device and then coaxial feed is given to this antenna through SMA connector.

Figure 12 shows the measured return loss profile of the antenna. At design frequency of 2.00 $\mathrm{GHz}$, it is obtained as $-32 \mathrm{~dB}$ i.e. minimum. We have obtained multibands with small bandwidth. The measured VSWR, as shown in Figure 13, is also within the arrange 1-2 
International Journal of Wireless \& Mobile Networks (IJWMN) Vol. 3, No. 5, October 2011

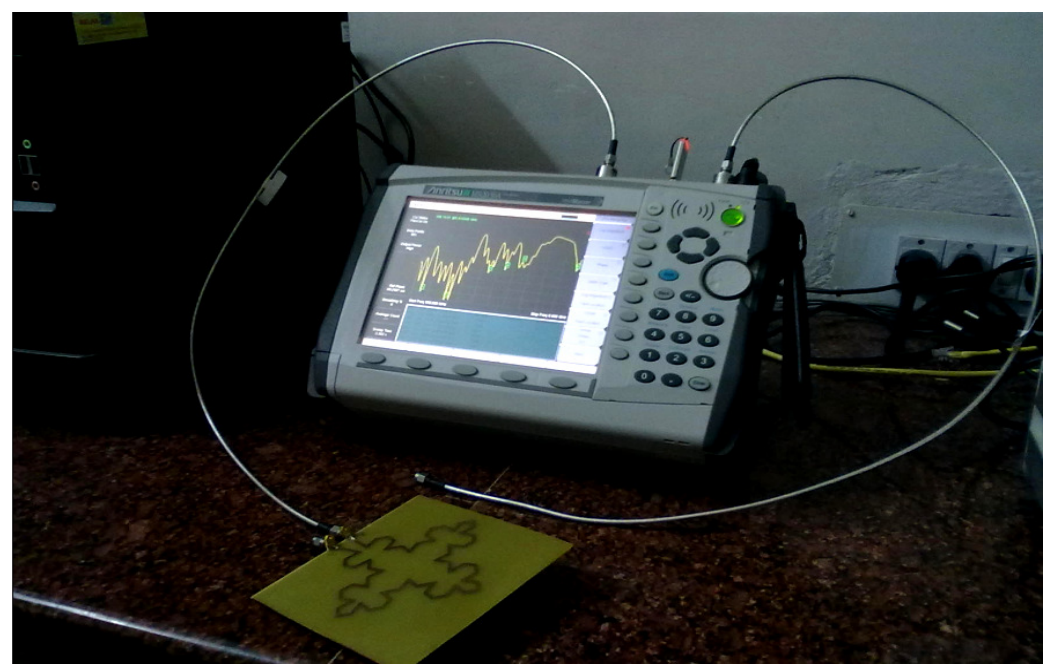

Figure 11. Laboratory setup for measurement of return loss and VSWR.

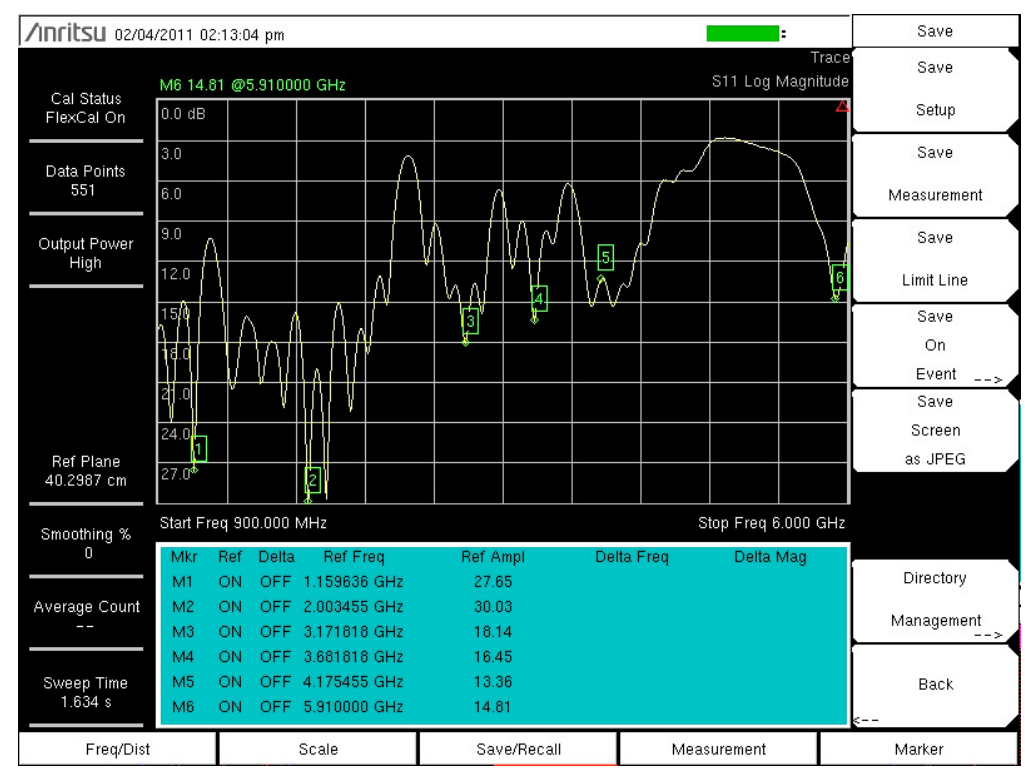

Figure 12. Measurement of return loss on VNA 
International Journal of Wireless \& Mobile Networks (IJWMN) Vol. 3, No. 5, October 2011

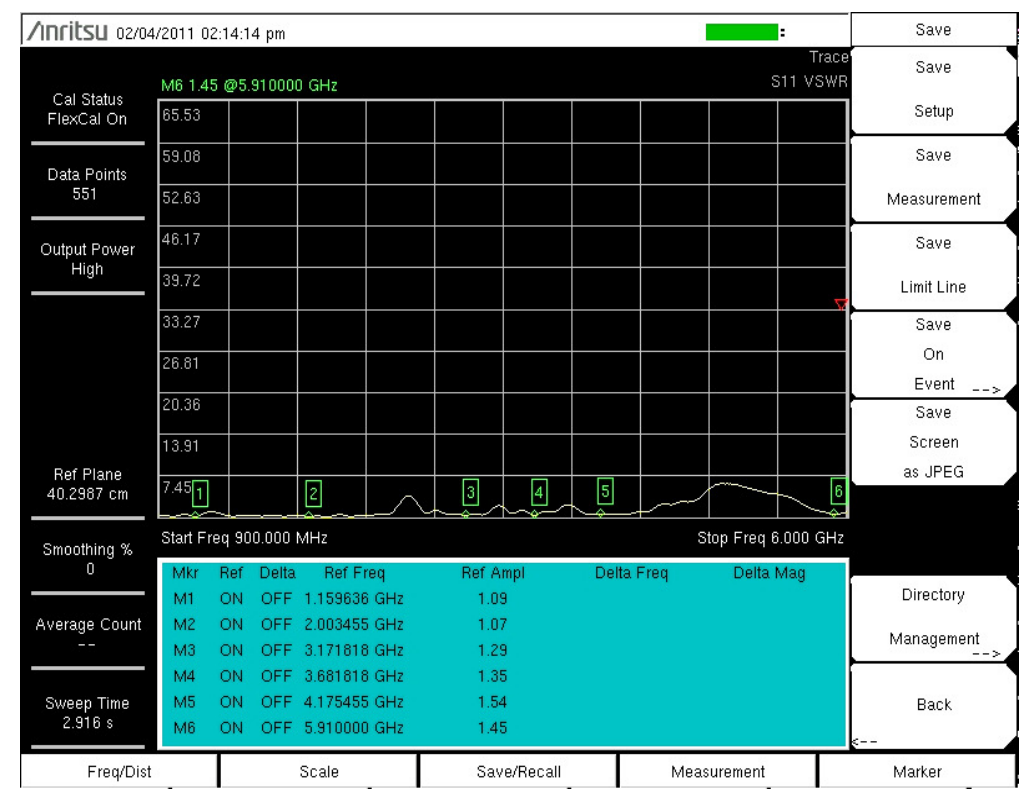

Figure 13. Measurement of VSWR on VNA

Comparisons of the simulated and experimental results were made and we found that there is a close agreement between the two as shown by Table 3 . The slight variation in results may be due to environmental conditions which could not be considered in simulation. Also during fabrication process, fringing edges of the patches may have irregularities due to which fringing field gets disturbed, resulting in shift in resonant frequencies. It has been observed that as we increase the iterations number of frequency band also increases.

Table 3: Comparison between Simulated results and Measured Return Loss

\begin{tabular}{|c|c|c|c|c|}
\hline Band No & \multicolumn{2}{|c|}{ Simulated results } & \multicolumn{2}{c|}{ Measured Results } \\
\hline & Centre Freq. & S11 in dB & Centre Freq. & S11 in dB \\
\hline I & 0.135 & -15.761 & 0.135 & -15.04 \\
\hline II & 2.01 & -33.304 & 2.03 & -30.04 \\
\hline III & 1.56 & -32.047 & 1.16 & -27.85 \\
\hline IV & 3.00 & -30.845 & 3.17 & -18.14 \\
\hline V & 4.2 & -29.70 & 4.17 & -13.36 \\
\hline VI & 5.625 & -23.13 & 5.91 & -14.01 \\
\hline VII & 8.19 & -14.554 & 8.19 & $* *$ \\
\hline & & & & \\
\hline
\end{tabular}

Radiation pattern are simulated and investigated for all the five frequency bands as shown in Figure 14. It is deduced that as the frequency is increasing radiation pattern changes to provide higher directivity and gain. Overall gain of this antenna is good at higher frequency bands as compared to the lower frequency bands. For lower frequency bands, upto $4 \mathrm{GHz}$ gain is below 4 $\mathrm{dBi}$ and for higher frequency ranges upto $8.2 \mathrm{GHz}$, gain is above $4 \mathrm{dBi}$. Highest gain was observed at frequency of $8.2 \mathrm{GHz}$ i.e. $7.92 \mathrm{dBi}$. 
International Journal of Wireless \& Mobile Networks (IJWMN) Vol. 3, No. 5, October 2011

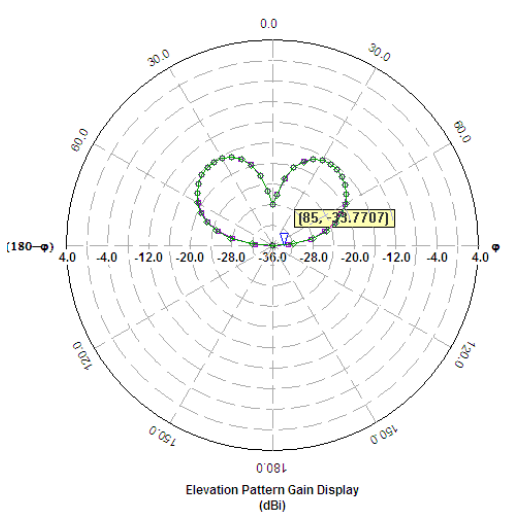

(a) Frequency $=2 \mathrm{GHz}$.

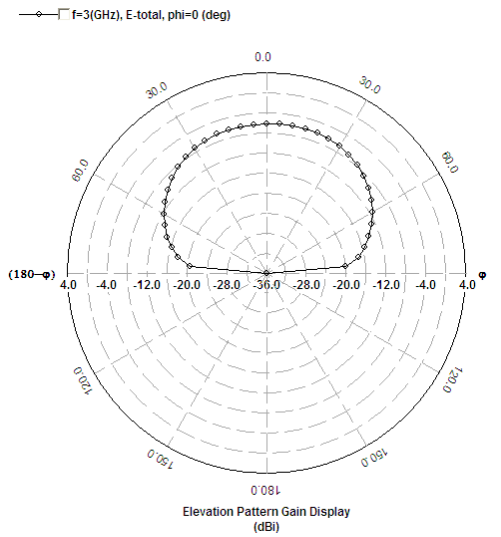

(b) Frequency $=3 \mathrm{GHz}$.

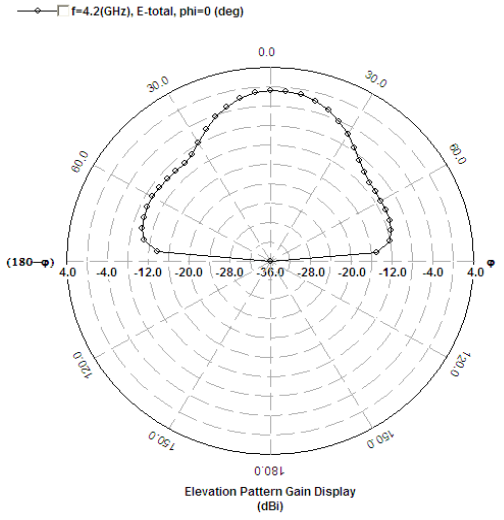

(c) Frequency $=4.2 \mathrm{GHz}$

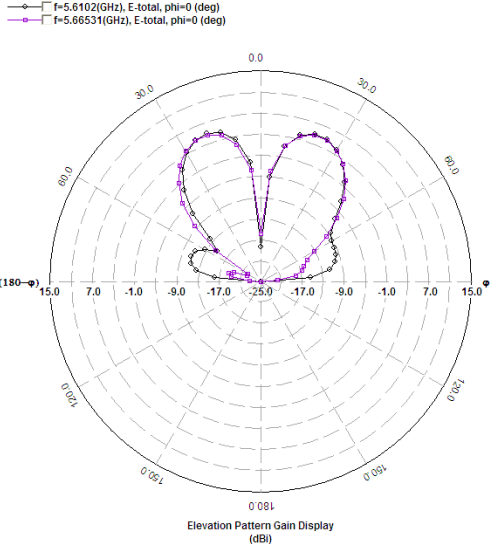

(d) Frequency $=5.61 \& 5.66 \mathrm{GHz}$

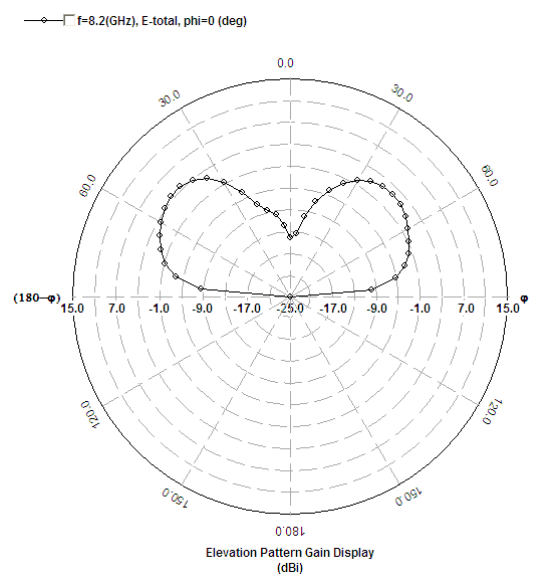

(e) Frequency $=8.2 \mathrm{GHz}$

Figure 14. Radiation pattern for 5 bands 
International Journal of Wireless \& Mobile Networks (IJWMN) Vol. 3, No. 5, October 2011

\section{Conclusion}

A novel prototype structure for Koch Loop Antenna was developed and experimentally proven to be adequate in terms of return loss. Seven resonant bands have been obtained by simulation $\&$ measurement on VNA, for this antenna. The VSWR of the designed antenna is less then 2 for all 7 resonant bands of $135 \mathrm{MHz}, 1160 \mathrm{MHz}, 2030 \mathrm{MHz}, 3170,4171 \mathrm{MHz}, 5910 \mathrm{MHz}$. and $8190 \mathrm{MHz}$.

Experimentally it has been observed that fractal antenna is very good radiator as we measured return loss of $-30 \mathrm{~dB}$ on VNA, it is obtained at the frequency for which Koch dipole is designed. Other bands observed are below and above this central frequency, it is because of the variation in the length of dipole. We may conclude that we obtain more than one resonant band due to the facts, firstly, each small element acts as a separate radiating dipole element; secondly, entire loop as a radiating element. Besides, each small element contributes towards the increase in electrical length of antenna to increase radiating field $E_{\theta}$.

Designed Koch Loop Antenna has possibility of being optimized in terms of return loss and number of narrow frequency bands. It is observed that by varying the width of strip of or small variations in the geometry of the antenna does not change the frequency characteristics of the antenna. The range of the frequency bands is within the wireless communication bands of Wi-fi, WiMAX, Bluetooth and wireless LAN etc.

\section{ACKNOWLEDGEMENT}

We wish to acknowledge, Dr. S.S. Pattnaik (NITTTR, Chandigarh) for his support and Dr. O P $\mathrm{N}$ Calla for the motivation to do research in this area.

\section{REFERENCES:}

[1] T. Tiehong and Z. Zheng, " A Novel Multiband Antenna: Fractal Antenna", Electronic letter, Proceedings of ICCT - 2003, pp: 1907-1910.

[2] D. H. Werner and S. Ganguly, “An Overview of Fractal Antennas Engineering Research”,IEEE Antennas and Propagation Magazine, vol. 45, no. 1, pp. 38-57, February 2003.

[3] J. Gianvitorio and Y. Rahmat, "Fractal Antennas: A Novel Antenna Miniaturization Technique and Applications", IEEE Antennas and Propagation Magazine, vol. 44, No. 1, pp: 20-36, 2002.

[4] K. Falconer, "Fractal Geometry: Mathematical Foundation and Applications", John Wiley, England, 1990.

[5] S.H Zainud-Deen, K.H. Awadalla S.A. Khamis and N.d. El-shalaby, March 16-18, 2004. Radiation and Scattering from Koch Fractal Antennas. 21st National Radio Science Conference (NRSC), B8 - 1-9.

[6] P. S. Addison, "Fractals and Chaos: An Illustrated Course", Institute of Physics Publishing Bristol and Philadelphia, 1997.

[7] G. J. Burke and A. J. Poggio "Numerical Electromagnetic Code (NEC)-Program description", January, 1981, Lawrence Livermore Laboratory.

[8] C. A. Balanis, “Antenna Theory: Analysis and Design”, 2nd ed., Wiley, 1997.

[9] Cohen N.L. 2005, New era in military antenna design, Defense Electronics.

[10] Nemanja POPRZEN \& Mico GACANOVIC, Fractal antenna: Design, Characteristics and Application.

[11] Carles Puente and Angel Cardama, "The Koch Monopole: A small fractal antenna", IEEE transaction on antenna and propagation, vol 48, no. 11 Nov 2000. 


\section{Author}

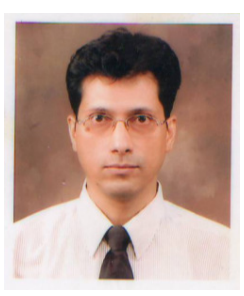

Mr. Rajeev Mathur is Associate Professor in the Department of Electronics \& Communication, GITS Udaipur and is presently pursuing Phd. on the "Design \& Development of Advanced Antenna Techniques for the performance enhancement of wireless MIMO communication systems". He received his M.E Degree from National Institute of Technical Teachers Training \& Research, Chandigarh, INDIA, in 2008 and B.E. degree in Electronics from VRCE, Nagpur in 1991. He worked with PUNWIRE Mobile Communication System Ltd, Chandigarh, INDIA for 6 Years. He was also Member of Board of management of JN University. His area of research is Antenna \& Microwave Engineering, Metamaterials. He has published 9 national papers and 5 international papers.

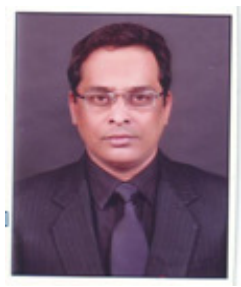

Dr. Sunil Joshi is Associate Professor in the department of Electronics \& Communication Engineering, College of Technology \& Engineering, Maharana Pratap University of Agriculture \& Technology, Udaipur, India. His research areas include Multiple Input Multiple Output Wireless Broadband Systems and Millimeter Wave Technology.

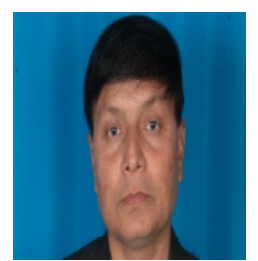

Dr.(Prof.) Krishna Chandra Roy, Principal \& Professor in Deptt. Of Electronics and Communication Engg. Pacific Institute of Technology, Udaipur INDIA. He is M.Sc. (Engg.), Ph.D "Digital Signal Processing in a New Binary System". He has 15 Years of experience and has published 55 International and National paper and 2 books. Guest Speaker and Members of Advisory Committee of different National and International Conferences. 